\title{
Assessing the impact of major historical events on urban landscapes via local entropy measures
}

\author{
Matteo Mazzamurro \\ Warwick Institute for Science of Cities, University of Warwick \\ Coventry, United Kingdom \\ matteo.mazzamurro@warwick.ac.uk
}

\author{
Weisi Guo \\ Centre for Autonomous and Cyber-Physical Systems \\ Cranfield University, United Kingdom \\ weisi.guo@cranfiel.ac.uk
}

\begin{abstract}
In this paper we show how Shannon entropy, an intuitive and versatile measure of uniformity of a probability distribution, can be adapted to quantify the heterogeneity of land use and population density in and around human settlements. Using a raster data set of estimates of historical population density and land use, we show that local entropy measures capture salient aspects of the evolution of urban systems. Through the case studies of the UK, India, and Italy we reconnect the temporal evolution of the measures to some of the main socioeconomic and political changes and epidemic events these countries went through during the last three centuries. We argue that the diffusion of technological innovations is more apparently correlated to changes in the measures than epidemic events in themselves. We discuss the potential significance and limitations of this finding in understanding changes in urban systems in the context of the ongoing COVID-19 pandemic.
\end{abstract}

Index Terms-data analysis; resilience; land use; entropy

\section{INTRODUCTION}

Since their emergence, cities have been the main places of exchange and interaction for the human race. More recently, with over $50 \%$ of the world population living in urban areas, cities have also become its primary abode. From being local centres of trade, craftsmanship, and administration, cities have seen their functions and structures multiply and become more complex. With urbanisation rates increasing worldwide, the destiny of Man seems to be that of becoming more and more a Homo Urbanus [1]. Yet, the growth of cities has hardly ever been a smooth process: wars, epidemics, political changes, and technological innovations have all impacted the pace and form of urbanisation. Most recently, the ongoing Covid-19 pandemic has put into question the seemingly irreversible trend towards greater urbanisation that has characterised much of the world, albeit with different onsets and speed, since the industrial revolution began in the 1700s.

Urbanisation, in both its dimensions of increased land consumption and growing density, provides unique challenges in time of pandemics, as COVID-19 has shown. On the one hand, the virus has been reported to spread faster in larger cities compared to smaller centres in the first weeks of the pandemic [2]. On the other hand, a primal role in disease emergence and spread is attributed to the sprawling urban fringes, where zoonoses are made more likely by proximity with agricultural and wild environments [3], and whose unboundedness pushes their residents and workers alike to move around vaster areas, thus making it more difficult to limit contagion [4].

The possibility afforded by telecommunication technologies to pursue home-working has led some architects and urbanists to call for a rethinking of urbanisation. Alternative models were proposed, which rejected the need of physical density to achieve the relational density and the agglomeration effects which constitute the rationale behind the existence itself of cities. Koolhaas and Boeri, amongst other, have argued that the future lies in the rediscovery of villages, especially those located in declining internal areas, and the return of population to rural areas [5], [6].

Yet their visions for the future of cities have been accused of naivety [7], as they neglect the complex long-standing reasons that have driven the abandonment of villages and rural areas in the last decades, such as the expansion into rural areas of typically urban economic, political and cultural models, that has impacted their values, identity and ambitions. Furthermore, these proposals ignore the fact that village depopulation does not happen in a homogeneous fashion. In the US, for instance, rural areas in proximity to metropolitan counties are less affected by decline, as are rural areas that have shifted their economic focus from agricultural production to recreational activities or specialised as retirement destinations [8].

Early data analyses do not support the idea of a consistent return of population to rural areas during the pandemic, and depict instead a much more heterogeneous situation. Using mobility data from Facebook's Data for Good initiative, [9] shows that during the first lockdown, India witnessed a sharp decrease in Facebook users in urban areas (4-11\%), paralleled by an increase in their number in rural areas (7\%). Though Facebook user data may not be representative of the population as a whole, the finding suggests that a large displacement of people towards rural and peripheral areas may have taken place during the lockdown, mostly attributed to the return of migrant workers residing in cities to their places of origin, often smaller, remote localities.

The number of Facebook users was also used to study the change in population density in the UK from March 2020 to September of the same year, evidencing that larger cities (and London in particular) saw a strong decline in users, as opposed to smaller towns, especially along the coast, that witnessed an increase across the period [10]. 
On the other hand, Facebook's mobility data in Italy showed that people did not move considerably within the country during the first lockdown. Peripheral rural areas saw only marginal increase in the total number of users, whilst most users who appeared to have moved out of large cities, moved to mid-sized towns in their vicinity and urban belts, reflecting a halt in the established commuting patterns rather than a rural exodus [11]. In fact, it was argued, only a minority of highincome, knowledge-intensive workers could afford moving to rural areas permanently, provided they wanted to.

The national differences of the short term impact of the pandemic on the population distribution suggest that a more nuanced and context-informed approach is needed to understand the impact that an event of this kind might have on the future evolution of the urban system.

Whilst it is not possible at this stage to know for sure how cities will change after this tumultuous present, looking at the past may help us identify what events have been the main drivers in shaping urban form thus far, and whether epidemics feature as one of them. It is with this idea in mind that in this paper we look at the evolution of two fundamental aspects of urban form: land use and population density, in different countries around the world from 1700 to present day and correlate major historical events (political changes, technological innovations, and epidemics) to urbanisation trends. We do so through Shannon entropy-based measures of the local heterogeneity of land use and population density in and around human settlements. To our best knowledge this paper constitutes the first application of spatial entropy measures to study the evolution of systems of settlements at the national scale from a long-term historical perspective.

\section{DATA}

For this paper, we use the HYDE 3.2 data set [12]. This raster data set provides worldwide land use and population density estimates from 10,000BCE to 2015CE, with more frequent and accurate data in more recent years. HYDE 3.2 allows to distinguish between several categories and subcategories of land use, including the following 7 , that we take as the basis for our analysis: urban areas, dense settlements, villages, cropland, rangeland, semi-natural, and wild lands. Cells corresponding to seas and oceans are unclassified. Estimates of the total population counts and density for each cell are also given. The resolution of the longitude/latitude grid, is $5^{\prime} \times 5^{\prime}$, corresponding to roughly $85 \mathrm{~km}^{2}$ around the equator. Other data sets such as [13], [14], and [15] also provide population density grid with higher resolution, but the latter two do not provide historical estimates, and the former only provides them starting from 1970, making them unsuitable for our long term analysis. It is important to notice that the data estimation procedure detailed in [12] assumes a functional relation between urban population densities and urban land area that may not be accurate for individual cities. Yet, given our focus on larger areas and averaging procedures, we deem the data set suitable for our scopes.

\section{Methodology}

We assess the level of heterogeneity and disorder in land use and population density in and around human settlements via local entropy measures adapted to the raster form of the above described data set.

\section{A. Cell Neighbourhoods}

For each cell $(i, j)$ in the raster data set, we consider the neighbourhoods $C_{(i, j)}^{n}$ formed by the cell itself and its closest, $n-1=4,8$ or 20 closest neighbours, as measured by greatcircle distance between the centres of the cells. The resulting neighbourhoods correspond to discs around the centre of the cell $(i, j)$, having radii $8 \mathrm{~km}, 12 \mathrm{~km}$ and $20 \mathrm{~km}$ at the equator, respectively (see Fig. 1). The neighbourhood $C_{(i, j)}^{n}$ acts as an observation windows of size $n$ around the cell $(i, j)$.
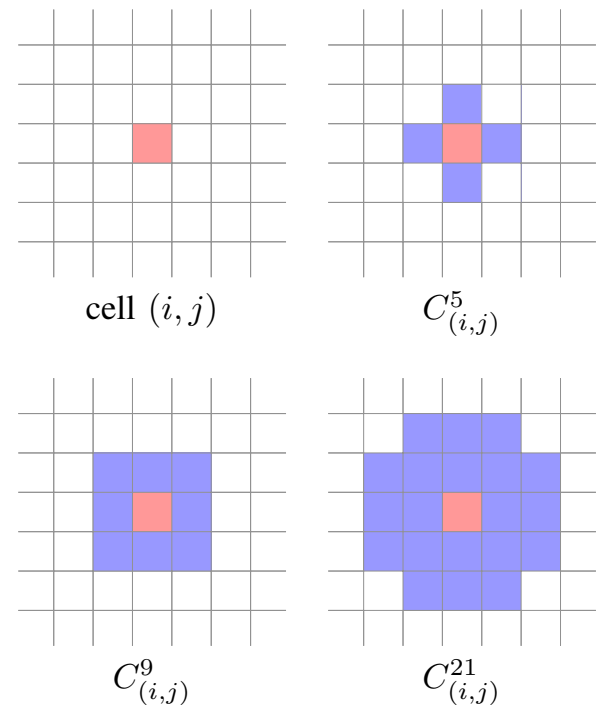

Fig. 1. Neighbourhoods $C_{(i, j)}^{n}$ of a cell $(i, j)$ for $n=5,9$ and 21 .

\section{B. Local entropy}

Consider a region $R$ of the world (e.g. a country), and fix some window size $n \in\{5,9,21\}$. Let $(i, j)$ be any cell whose land use classifies it as a human settlement (urban, dense settlement, or village). Suppose $n^{\prime}$ of the cells in its neighbourhoods $C_{(i, j)}^{n}$ fall within $R$ and on land. Let $p_{k}$ be the fraction of these $n^{\prime}$ cells in $C_{(i, j)}^{n}$ with land use $k$, where $k$ ranges along the aforementioned 7 categories, (so that $\left.\sum_{k} p_{k}=1\right)$. We define the land use local entropy $E_{(i, j)}^{n}$ of the cell $(i, j)$ with respect to its $n-1$ closest neighbours as the Shannon entropy [16]

$$
E_{(i, j)}^{n}=-\sum_{k} p_{k} \log _{2}\left(p_{k}\right) .
$$

The application of Shannon entropy to spatial urban data has been pioneered by [17], and since then replicated in a number of studies, including [18], [19].

Shannon entropy is an intuitive measure of the heterogeneity of the distribution $\left\{p_{k}\right\}_{k}$. The minimum value of the entropy $\left(E_{(i, j)}^{n}=0\right)$ is achieved when all cells in the neighbourhood 
$C_{(i, j)}^{n}$ have the same land use as $(i, j)$, i.e. we have a homogeneous landscape around $(i, j)$. The more heterogeneous the landscape is, the larger the value of the entropy. The maximum possible value of $E_{(i, j)}^{n}$ depends on $n^{\prime}$, rather than $n$ directly.

For example, for any value of $n$, if the neighbourhood $C_{(i, j)}^{n}$ contains only $n^{\prime}=5$ cells falling on land and within the borders of the region $R$, the most heterogeneous case is the one in which the 5 cells have any 5 distinct land uses, i.e. $p_{k}=\frac{1}{5}$ for any 5 of the $k$ 's and $p_{k}=0$ for the remaining two, giving a maximum value of $\log _{2}(5)$.

Normalising the values of $E_{(i, j)}^{n}$ by the appropriate maximum values allows to avoid border effects and compare the local entropy at $(i, j)$ for different window sizes. The normalised values fall between 0 (complete homogeneity) and 1 (maximum heterogeneity). We use the normalised values to define a new raster of land use heterogeneity around human settlements (See, e.g., Fig. 3 in the Section V). Summing over all cells $(i, j)$, we obtain $E_{\text {land }}^{n}$, a measure of the total local entropy of human landscapes in $R$. Averaging over cells, we similarly obtain $\bar{E}_{\text {land }}^{n}$, a measure of the mean local entropy of urban landscapes in $R$.

By computing $E_{\text {land }}^{n}$ and $\bar{E}_{\text {land }}^{n}$ at different moments in time, it is finally possible to study the evolution of the local heterogeneity of land use in the region $R$.

In a completely analogous way, we classify the density raster data into different categories, and study the evolution of the local entropy of the population density in time. For simplicity and symmetry, here we choose 7 categories: zero density (uninhabited lands), densities between 1 and $50 \mathrm{inh} / \mathrm{km} 2$ (sparsely populated), 51 to 100 (moderate-low density), 101 to 200 (moderate-high density), 201 to 500 (high density), 501 to 1,000 (very high density), and 1,001 or more inh $/ \mathrm{km} 2$ (extremely high density). We proceed as before calculating the local entropy of the density in the neighbourhoods of each cell classified as human settlement, and normalising the values accordingly. Summing over the cells we obtain $E_{\text {density }}^{n}$, a measure of the total local entropy of population density in $R$. Averaging, we obtain $\bar{E}_{\text {density }}^{n}$, a measure of the mean local entropy of population density in $R$.

\section{EXAMPLE}

As a simple example, we consider the two 9-cell regions in Fig. 2. As reference systems, we take the top cell in each region to be $(1,1)$. We choose $n=5$ as the window size. In the region in Fig. 2a, we have agricultural land with a moderately dense settlement at its centre. In this case, only the central cell $(2,2)$ contains a human settlement, so we only deal with $C_{(2,2)}^{5}$. Here $n^{\prime}=5$ and $p_{\text {dense }}=\frac{1}{5}, p_{\text {cropland }}=\frac{4}{5}$, with $p_{k}=0$ for every other land use $k$. Thus

$$
E_{(2,2)}^{5}=\log _{2}(5)-\frac{8}{5} \text {. }
$$

Normalising by the maximum value $\log _{2}(5)$, we obtain

$$
E_{\text {land }}^{5}=\bar{E}_{\text {land }}^{5}=\frac{\log _{2}(5)-8 / 5}{\log _{2}(5)} \approx 0.31 .
$$

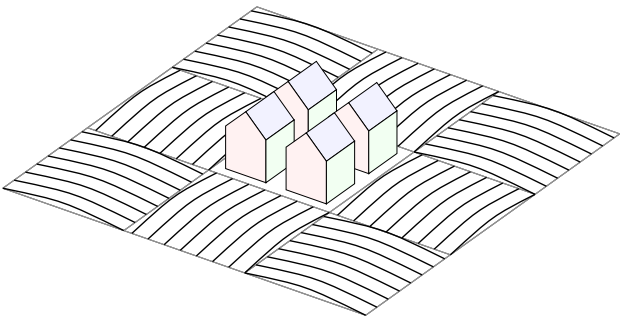

(a) A simple region: a moderate density settlement surrounded by fields

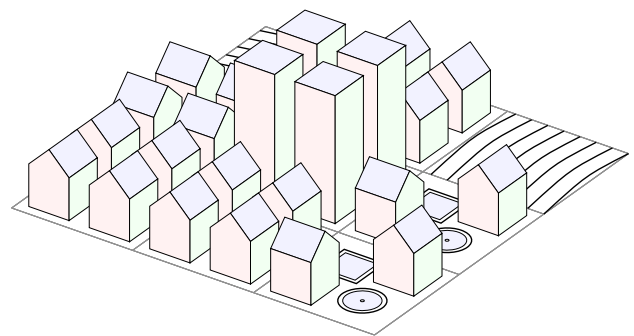

(b) A more complex region: a mixture of high, moderate and low density areas, as well as agricultural land.

Fig. 2. Examples of a simple and a more complex region.

In Fig. 2b, we have a more complex region with one urban cell at the centre $(2,2)$, four cells with dense settlement around it $\{(1,2),(2,1),(3,1),(3,2)\}$, two low density villages $\{(2,3),(3,3)\})$ and two cells of cropland $\{(1,3),(3,1)\}$. In this case, we have to compute $C_{(i, j)}^{n}$ for all cells except the two allocated to cropland. As an example of cell on the border, consider $(1,2) . C_{(1,2)}^{5}$ contains $n^{\prime}=4$ cells, with $p_{\text {urban }}=\frac{1}{4}$, $p_{\text {dense }}=\frac{1}{4}, p_{\text {cropland }}=\frac{1}{2}$, and $p_{k}=0$ for all other land use $k$. Hence

$$
E_{(1,2)}^{5}=\frac{3}{2},
$$

and the normalising constant is $\log _{2}(4)=2$.

After computing and normalising appropriately each cell entropy value, we sum or average over the 7 cells with human settlements, and obtain

$$
E_{\text {land }}^{5} \approx 4.2, \text { and } \bar{E}_{\text {land }}^{5} \approx 0.6,
$$

reflecting the fact that this region is considerably more heterogeneous than the top one, both overall, and on average around each settled cell.

\section{Results}

We apply the above methodology to study the change in time of the local entropy of land use and population density in the UK, India, and Italy, the three countries for which the impact of Covid-19 on the distribution of population was discussed in Section I. We consider the years from 1700 to 2015, a period in which the countries were shaken by important socioeconomic changes (e.g., the industrial revolutions), political events (e.g., the colonisation and decolonisation of India, the rise of Fascism, the World Wars), and at least two major epidemics (the Bubonic Plague of 1894-1901 [20], and the Spanish Flu in 1918-1920). 


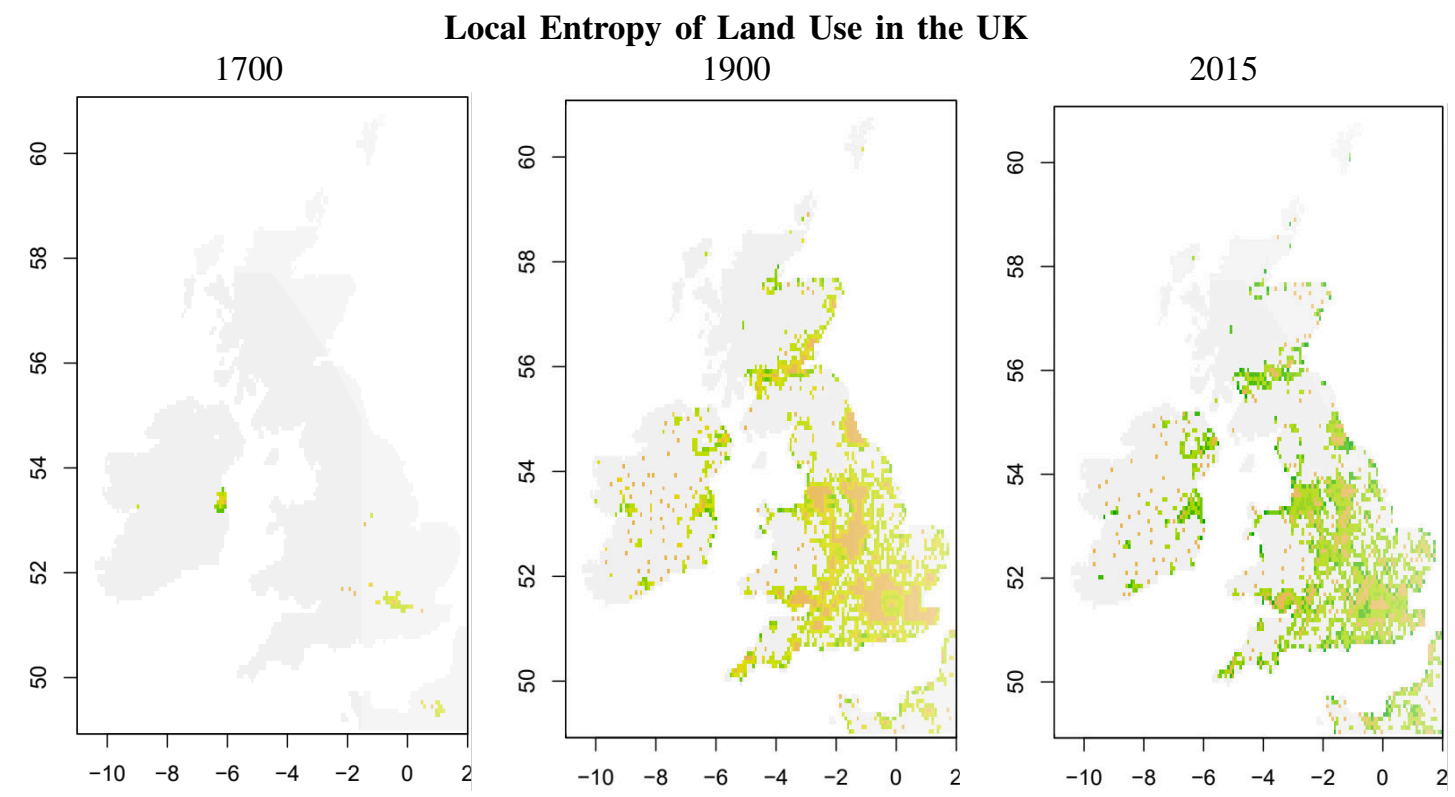

Local Entropy of Land Use in India

1700

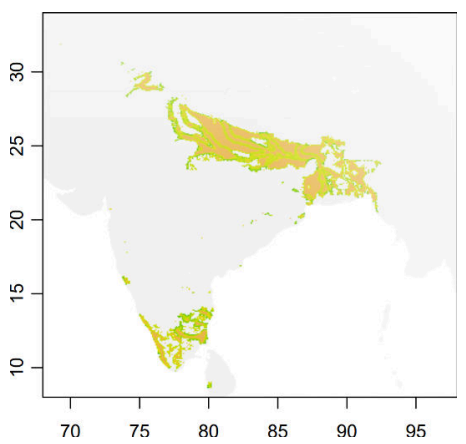

1900

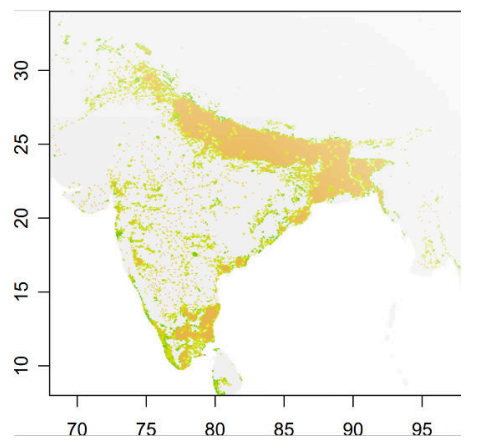

2015

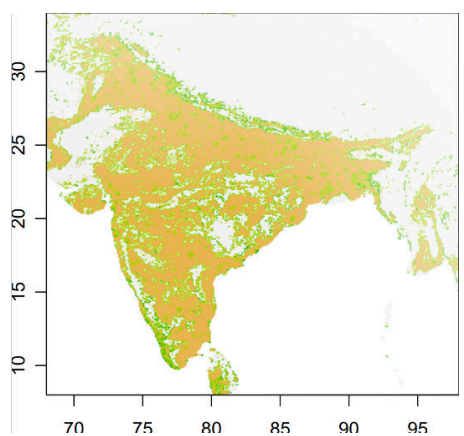

Entropy

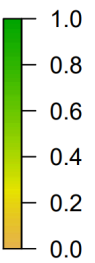

$\square$ no settlements

Local Entropy of Land Use in Italy
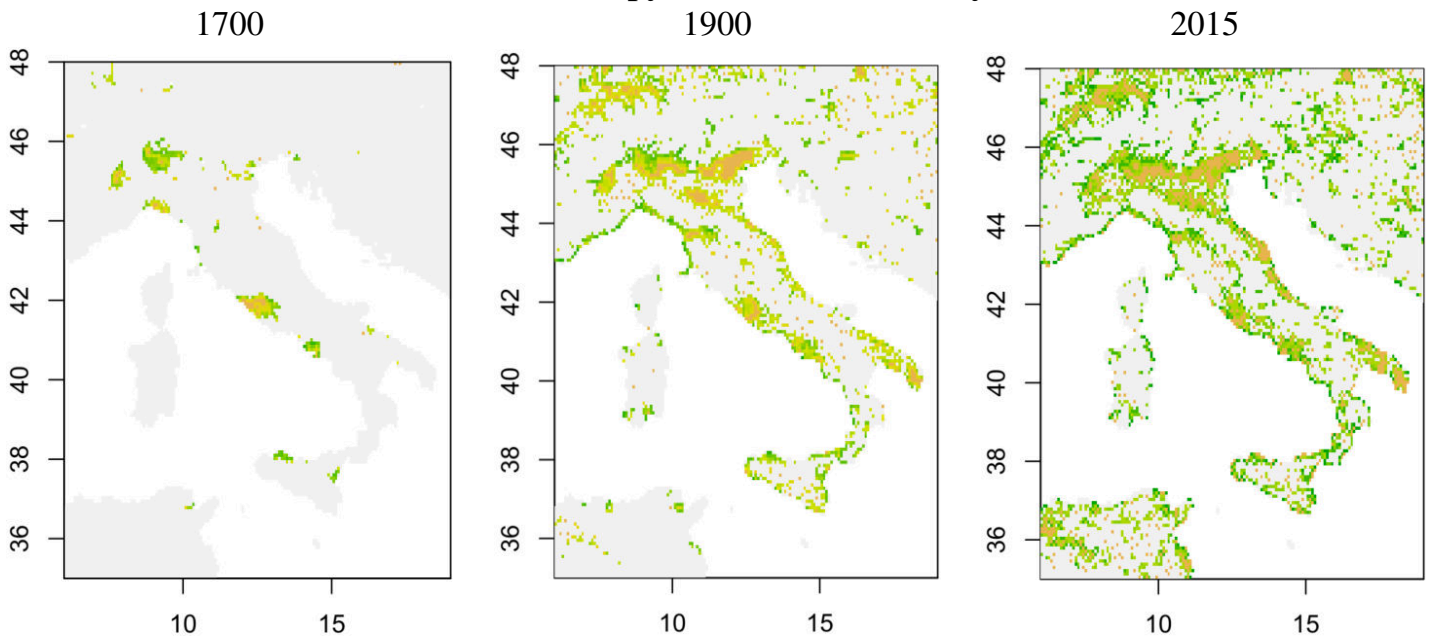

Fig. 3. Local Entropy of Land use in the UK, India, and Italy, in 1700, 1900, and 2015. The window size is $n=5$ 
Total local entropy of land use in the UK

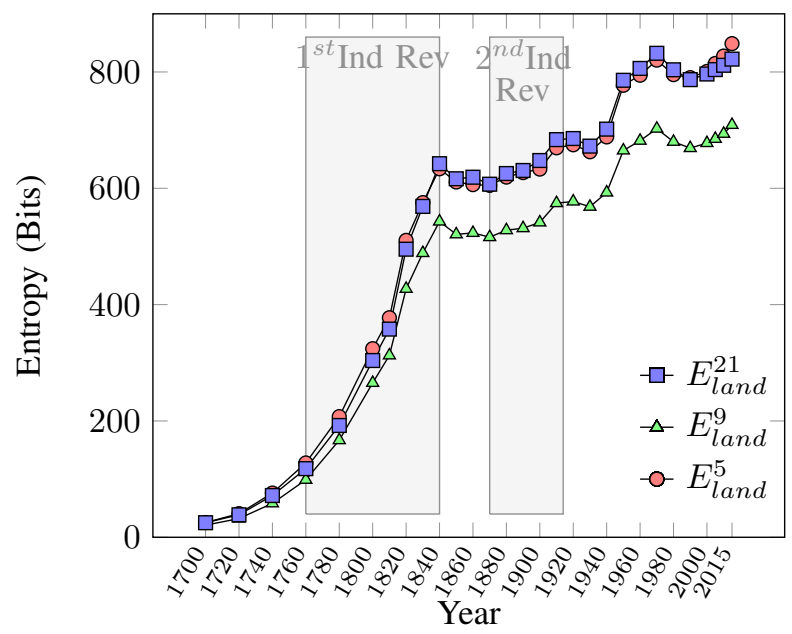

(a) Total local entropy $E_{\text {land }}^{n}$ of land use
Total local entropy of population density in the UK

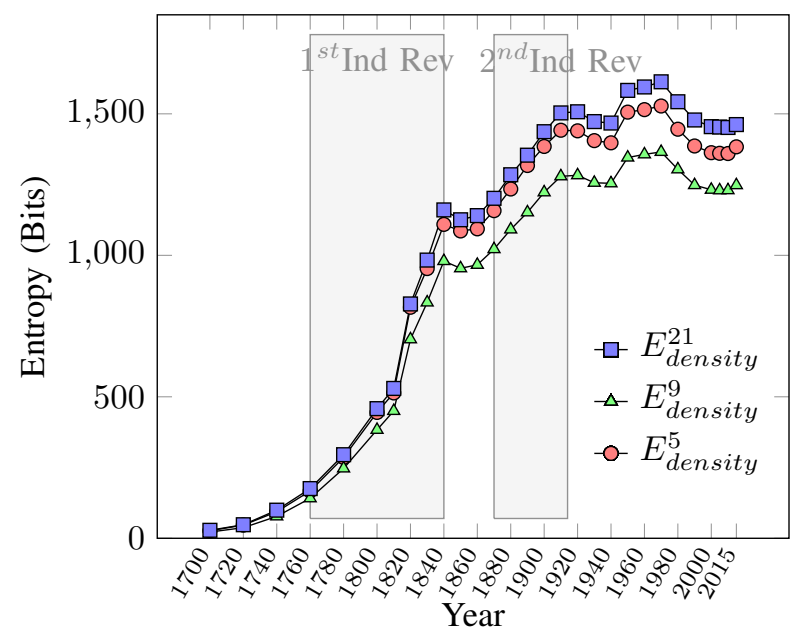

(b) Total local entropy $E_{\text {density }}^{n}$ of population density

Fig. 4. Total local entropy $E_{\text {land }}^{n}$ of land use and $E_{\text {density }}^{n}$ of population density in the UK, for $n=5$, 9, and 21 nearest neighbours. Whilst differences in absolute values exist, the general trends are not impacted by the window size and are mostly consistent between the measures.

\section{Mean local entropy of land use in the UK}

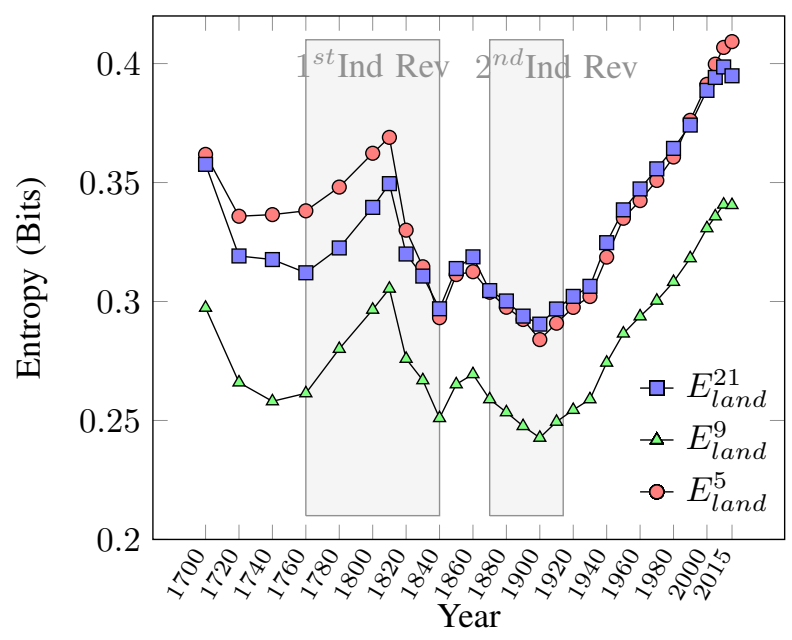

(a) Mean local entropy $\bar{E}_{\text {land }}^{n}$ of land use
Mean local entropy of population density in the UK

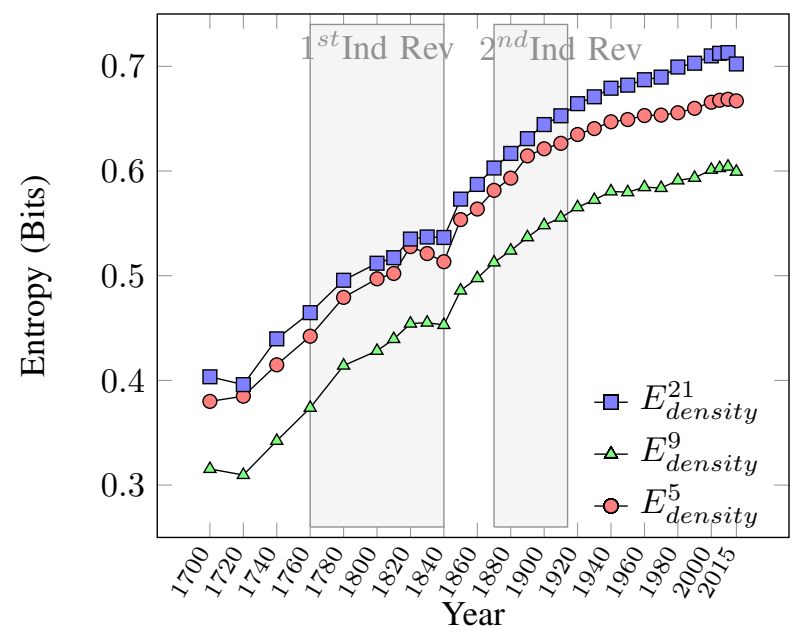

(b) Mean local entropy $\bar{E}_{\text {density }}^{n}$ of population density

Fig. 5. Mean local entropy $\bar{E}_{\text {land }}^{n}$ of land use and $\bar{E}_{\text {density }}^{n}$ of population density in the UK, for $n=5$, 9, and 21 nearest neighbours. The general trends are not greatly affected by the window size but reveal important differences between the measures.

\section{A. Raster of local entropy}

Figure 3 shows the countries' raster of local entropy of land use in 1700, 1900 and 2015.

In the UK, after a dramatic expansion from 1700 to 1900, the number of cells occupied by human settlements remains roughly unchanged to 2015. As some of the cells previously classified as villages turn into dense settlements or are incorporated into the growing urban areas around major metropolises, their color shift from orange (low local entropy) to green (high local entropy), reflecting the growing heterogeneity in land use of the areas around them.

In Italy, a similar expansion is observed from 1700 to 1900 , but the expansion continues this date. The majority of new cells occupied by settlements appear in the vicinity of already established urban areas, especially in the Po Valley and along the coast. These cells are characterised by large local entropy, reflecting their nature of urban fringes.

In India, the Valley of the Ganges and the South were already hosting several settlements by 1700 . The period to 1900 sees the expansion of settlements especially along the coast. A great expansion of the settled areas in the interior follows. Most of the cells are classified as villages surrounded by other villages or cropland, and this is reflected by the predominance of low entropy (orange) cells. Nonetheless, higher values are observed in either more remote areas of the interior and along the Himalayas, where settlements border wilder landscapes, and around established large urban centres. 
Entropy of land uses in the UK, India, and Italy

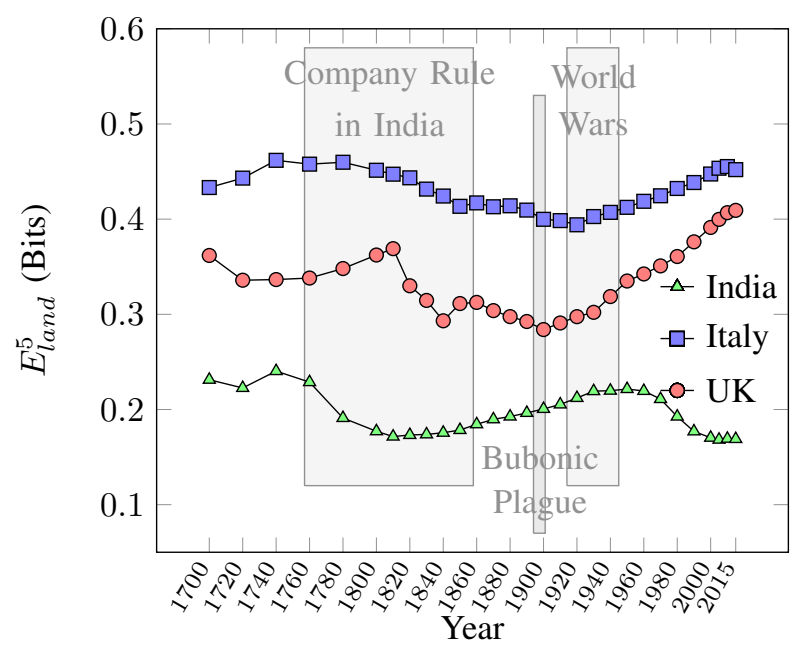

(a) Mean local entropy $\bar{E}_{\text {land }}^{5}$ of land use
Entropy of density in the UK, India, and Italy

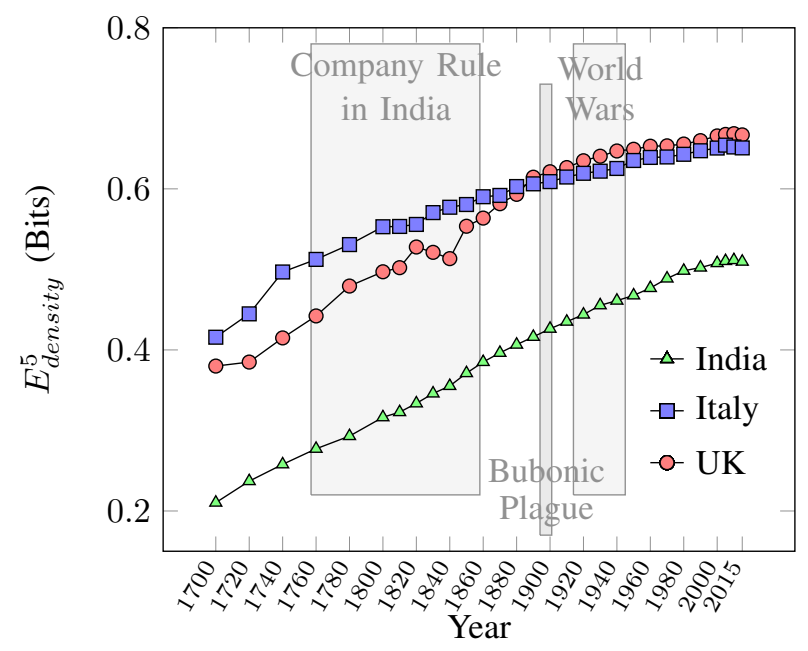

(b) Mean local entropy $\bar{E}_{\text {density }}^{5}$ of population density

Fig. 6. Comparison of local entropy $\bar{E}_{\text {land }}^{5}$ of land use and $\bar{E}_{\text {density }}^{5}$ of population density in the UK, India, and Italy.

\section{B. The impact of historical events on the local entropy}

In Fig. 4 we show the evolution of the total local entropy of land use $E_{\text {land }}^{n}$ and population density $E_{\text {density }}^{n}$ in the UK from 1700 to 2015 for various choices of window size $n=5,9$, and 21 . The value of $n$ is found not to affect the overall trends. The evolution of $E_{\text {land }}^{n}$ (Fig. 4a) and $E_{\text {density }}^{n}$ (Fig. 4b) reflects quite clearly the two industrial revolutions that the UK experienced between 1760-1840 and from the 1870s to the beginning of World War I in 1914. Both show a sustained growth in total local entropy, and were followed by more unstable decades of plateauing or slowly decreasing entropy values. Recent years are characterised by different behaviours in the two measures: whilst the entropy of land use continues to grow, the entropy of population density enters a phase of relative decline.

To distinguish the purely local effects from the mere expansion of the system of settlements, we look at the mean entropy $\bar{E}_{\text {land }}^{n}$ and $\bar{E}_{\text {density }}^{n}$ in Fig. 5. As above, the value of $n$ does not affect the main trends. These are not constant during the two industrial revolutions and may represent more nuanced consequences of industrialisation. The first industrial revolution sees at first a rapid increase in $\bar{E}_{\text {land }}^{n}$, followed by a sharp decrease starting from 1800 (Fig. 5a). This could reflect the fact that after a period of emergence of large number of new settlements, urban areas become better established and development happens mostly around them, creating more homogeneous urban and dense landscapes in their surroundings. The second industrial revolution, on the contrary shows at first a decline in $\bar{E}_{\text {land }}^{n}$, followed by a modest recovery toward the dawn of WWI after an all time minimum in 1900. This suggests that more complex phenomena were already in place concerning land use in the UK. This is a period of strong expansion of the railway and the decline in the measure may denote growing concentration of population in compact cities before the rise of urban sprawling, but more studies are necessary to confirm this hypothesis. The evolution of $\bar{E}_{\text {density }}^{n}$ during the first industrial revolution is of fast growth which plateaus towards the end of the period, followed by an increase in subsequent decades proceeding until present day (Fig. 5b). Our interpretation is that the technologies of the first industrial revolution allow only up to a certain maximum urban density, and, thus, stratification and heterogeneity of densities. It's only as new technologies emerge that maximum population density can again increase.

In Fig. 6 we perform a similar analysis for average entropy of land use $\bar{E}_{\text {land }}^{5}$ and population density $\bar{E}_{\text {density }}^{5}$ comparing the UK, India and Italy. The choice of $n=5$ is arbitrary, as also in these cases, it was found not to have a major impact on the overall trends. The change in $\bar{E}_{\text {land }}^{5}$ in India follows very closely the evolution of the political situation of the country (Fig. 6a). As rule of the British East India Company on India is established in 1757, the entropy of land use enters a period of fast decline. The measure returns to grow in the early 19th century and continues to do so until the end of WWII, at a time when India regain its independence. On the other hand, the evolution of $\bar{E}_{\text {land }}^{5}$ for Italy does not seem to be deeply affected by major events in the 19th century, including the unification of the country in 1861 , proceeding instead a steady decline begun in the mid 18th century. It is only in the 1920s that the measure returns to growth. This is a period which sees Italy under Fascist rule, fast demographic expansion after WWI, the growth of Rome as capital, and the foundation of a few new urban centres in swampy areas reclaimed for cultivation, but the growth in the measure may also reflect more general industrialisation and urbanisation trends seen elsewhere in Europe, including the UK. The evolution of $\bar{E}_{\text {density }}^{5}$ is monotonically increasing and relatively smooth for both India and Italy (Fig. 6b). 


\section{The impact of pandemics on the local entropy}

The effects of the Spanish Flu are difficult to extricate from those of the WWI, to which it immediately followed. On the other hand, the impact of the Bubonic Plague, which ravaged India from the end of the 19th century, seem to be negligible on existing trends. Whilst this does not constitute evidence that the current pandemic will not have a deeper impact on current urbanisation trends, it suggests that the direct impact of pandemics so far on the entropy of urban landscapes and population density may not have not been such to offset other established trends. It is rather the diffusion of technological innovation that seems to correlate more strongly with the evolution of an urban system, in good accord with the theory of innovation waves [21]. Whether, though, pandemics may create the condition for political, social, and technological changes to happen, which may in turn affect urbanisation, is a more complex question to answer, and other examples in history, such as the Justinian Plague and the Black Death, seem to suggest that this may well be the case [20].

\section{Discussion AND APPLICATIONS TO SMART CitiES}

It is too early to make predictions on the long-term effect that the pandemic will have on current patterns of urbanisation. Looking at the past confirms that correlation, let alone causation, between major events and changes in urban form are often far from obvious. As such, a long term historical vision help to shed some light on the inherently unpredictable nature of urbanisation.

Large cities have certainly lost some of their attractiveness [22]. Yet it should not be forgotten that all cities are, in virtue of their density and enhanced social contact, impractical places to live in without technological intervention [23]. Technologies and timely policies, such as app-based trackers, temporary social-distancing-based crowd management, and testing facilities, can alleviate the challenges of a pandemic, as shown in the case of the very dense urban environments of Singapore and South Korea [24]. Perhaps in the future health-tracking technologies will be as ubiquitous as sewage and water pipes are in many cities today.

And if indeed COVID-19 will lead, as some suggested, to a rediscovery of rurality and smaller centres, the main question is how to funnel this shift to the development of more balanced and equitable system of settlements. Of the four scenarios proposed in [25] for the future of UK cities, none predicts that high paid knowledge workers will consider relocating to deprived areas of the country, thus boosting their economy, unless incentives are offered to them. Instead, the impact of the pandemic could maintain or even exacerbate existing patterns of inequality, benefiting mostly already affluent suburbs or smaller towns.

COVID-19 shows us that smart cities solution should be devised on the one hand at managing growing populations in cities, but also at tackling their possible depopulation and growth of disorder, allowing rapid and, as much as possible, equitable reorganisation of systems of settlements and efficient redistribution of resources.

\section{CONCLUSION}

In this article, we have shown that past changes in the local entropy of human landscapes are correlated to the diffusion of technological innovations and, to a lesser extent, major political events, while the impact of pandemics is less apparent or at least indirect. Future efforts should be directed at corroborating the validity of entropy measures as methodological tools via comparisons with other measures, for instance spatial autocorrelation. Examining the diffusion of specific innovations, such as transport technologies (railways, cars), will be essential to clarify the nature of the observed correlations with the final goal of establishing causation mechanisms.

\section{REFERENCES}

[1] P. Crane and A. Kinzig, "Nature in the metropolis," Science, vol. 308, no. 5726 , pp. $1225-1226,2005$.

[2] A. Stier, M. Berman, and L. Bettencourt, "Covid-19 attack rate increases with city size," Mansueto Institute for Urban Innovation Research Paper Forthcoming, 2020.

[3] C. Connolly, R. Keil, and S. H. Ali, "Extended urbanisation and the spatialities of infectious disease: Demographic change, infrastructure and governance," Urban studies, vol. 58, no. 2, pp. 245-263, 2021.

[4] S. Biglieri, L. De Vidovich, and R. Keil, "City as the core of contagion? repositioning covid-19 at the social and spatial periphery of urban society," Cities \& Health, pp. 1-3, 2020.

[5] S. Boeri, "Via dalle città-nei vecchi borghi c'è il nostro futuro," 20April-2020.

[6] C. Piccoli, "Rem koolhaas: "la campagna ci salverà"," 8-May-2020.

[7] G. Cotella and E. V. Brovarone, "Questioning urbanisation models in the face of covid-19," TeMA-Journal of Land Use, Mobility and Environment, pp. 105-118, 2020.

[8] K. M. Johnson and D. T. Lichter, "Rural depopulation: growth and decline processes over the past century," Rural Sociology, vol. 84, no. 1, pp. 3-27, 2019.

[9] E. Denis, O. Telle, S. Benkimoun, P. Mukhopadhyay, and S. Nath, "Mapping the lockdown effects in india: how geographers can contribute to tackle covid-19 diffusion," The Conversation, 2020.

[10] U. O. of National Statistics, "Coastal towns in england and wales: October 2020," 2020

[11] P. Beria and V. Lunkar, "Presence and mobility of the population during the first wave of covid-19 outbreak and lockdown in italy," Sustainable Cities and Society, vol. 65, p. 102616, 2021.

[12] K. Klein Goldewijk, A. Beusen, J. Doelman, and E. Stehfest, "Anthropogenic land use estimates for the holocene-hyde 3.2," Earth System Science Data, vol. 9, no. 2, pp. 927-953, 2017, accessed 02-May-2021.

[13] CIESIN - Columbia University, "Global population count grid time series estimates," 02-May-2021.

[14] A. N. Rose, J. J. McKee, K. M. Sims, E. A. Bright, A. E. Reith, and M. L. Urban, "Landscan 2019," TN, 2020, accessed 02-May-2021.

[15] Facebook Connectivity Lab and CIESIN - Columbia University, "High resolution settlement layer (hrsl)," 2016, accessed 07-May-2021.

[16] T. M. Cover, Elements of information theory. John Wiley\&Sons, 1999.

[17] M. Batty, "Entropy in spatial aggregation," Geographical Analysis, vol. 8, no. 1, pp. 1-21, 1976.

[18] Y. Chen and L. Huang, "Spatial measures of urban systems: From entropy to fractal dimension," Entropy, vol. 20, no. 12, p. 991, 2018.

[19] D. G. Leibovici and C. Claramunt, "On integrating size and shape distributions into a spatio-temporal information entropy framework," Entropy, vol. 21, no. 11, p. 1112, 2019.

[20] M. Echenberg, Plague ports. New York University Press, 2007.

[21] D. Pumain, "An evolutionary theory of urban systems," in International and transnational perspectives on urban systems. Springer, 2018, pp. 3-18.

[22] M. Kowalewski, "Cities in lockdown: A few comments on urban decline and revival under the covid-19 pandemic," 2020.

[23] J. Jacobs, The economy of cities. Vintage, 2016.

[24] M. Acuto, "Covid-19: Lessons for an urban (izing) world," One Earth, vol. 2, no. 4, pp. 317-319, 2020.

[25] H. Farmer and O. Zanetti, "Escaping the city?" 2021. 
$2021-10-15$

\section{Assessing the impact of major historical events on urban landscapes via local entropy measures}

Mazzamurro, Matteo

IEEE

Mazzamurro M, Guo W. (2021) Assessing the impact of major historical events on urban landscapes via local entropy measures. In: 2021 IEEE international Smart Cities Conference (ISC2), 7-10 September 2021, Virtual Event https://doi.org/10.1109/ISC253183.2021.9562899

Downloaded from Cranfield Library Services E-Repository 